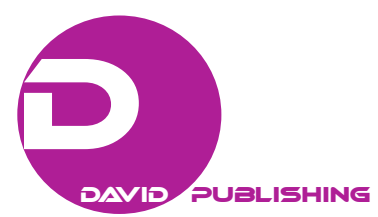

\title{
Influence of Institutional Support on Lecturers' Preparedness for E-learning at the University of Nairobi, Kenya*
}

\author{
Nicholas Kut Ochogo, Charles Mallans Rambo, Joyce Kanini Mbwesa, Paul Amollo Odundo \\ University of Nairobi, Nairobi, Kenya
}

\begin{abstract}
Institutional support is an essential antecedent for lecturer's preparedness for e-learning. The purpose of this study was to determine the influence of institutional support through appropriate training programs and budgetary allocation on lecturers' preparedness for e-learning at the University of Nairobi. A cross-sectional survey design was applied to source data from 212 lecturers and 96 administrative staff. Both quantitative and qualitative techniques were applied to process, analyze, and interpret the data. Quantitative analysis yielded descriptive statistics as well as cross tabulations with Chi-square $\left(x^{2}\right)$ statistic. The study found lack of significant relationship between lecturer's preparedness for e-learning and knowledge of the existence of an Information and Communication Technology (ICT) training program. The existing training program was still underdeveloped in terms of funding and strategies. Lecturers' preparedness for e-learning was also not significantly associated with perceived effectiveness of the existing training program; but was significantly related to training in software tools, as well as the source of funding for training. Although a team of ICT experts has been mandated to help academic staff prepare for e-learning, the team's functionality was constrained by under-funding and multiple roles. Lecturer's preparedness for e-learning also significantly associated with perceived adequacy of budgetary allocation for ICT program at the departmental level. Under-funding was a key factor constraining access to computers at the workplace, reliable internet connectivity and timely technical support, all of which significantly associated with lecturers' preparedness for e-learning. Universities in resource-poor settings should consider creating necessary partnerships to create avenues for information and resource sharing, revamp existing training programs with financial and human resources, create linkages with funding institutions, as well as improve budgetary allocation to ensure universal access to functional computers at the workplace, reliable internet connectivity and timely technical support.
\end{abstract}

Keywords: institutional support, preparedness, e-learning, training program, budgetary allocation

\footnotetext{
* Acknowledgement: Firstly, we are grateful to the University of Nairobi for granting the opportunity for to the first author to pursue the Ph.D. degree in Distance Education. Secondly, we thank all the participants who took their time to provide the requisite information. Thirdly, we are indebted to Tom Odhiambo, an independent research consultant for reviewing the manuscript.

Nicholas Kut Ochogo, Ph.D., University of Nairobi, Nairobi, Kenya.

Charles Mallans Rambo, Ph.D., University of Nairobi, Nairobi, Kenya.

Joyce Kanini Mbwesa, Ph.D., University of Nairobi, Nairobi, Kenya.

Paul Amollo Odundo, Ph.D., University of Nairobi, Nairobi, Kenya.

Correspondence concerning this article should be addressed to Charles Mallans Rambo, P.O. Box: 30197-00100, Nairobi, Kenya. Phone number: +254020318262, +2540721276663, and +2540733711255. E-mail: rambocharles@yahoo.com; crambo@uonbi.ac.ke.
} 


\section{Introduction}

The world has witnessed an unprecedented transition of university education from the traditional modes to technology assisted modes, particularly since the end of the Second World War (MENON Network, 2007). E-learning is a mode of instruction that involves the application of electronic media, including the internet, intranet, satellite broadcast, audio or video tapes, interactive television, or CD-ROMs (Trombley \& Lee, 2002; Tavangarian, Leypold, Nölting, \& Röser, 2004). E-learning improves teaching and learning processes by encouraging the use of modern instructional methods supported by Information and Communication Technology (ICT) tools (Selim, 2007). Statistical projections indicate that enrolment for university education through e-learning was expected to grow consistently from about 900,000 in 2003 to about 15.2 million learners by the end of 2012 (MENON Network, 2007). The ability of new ICT facilities to support multimedia resource-based teaching and learning is fundamental to the growing interest in e-learning world over (Farahani, 2003; Omwenga, 2004).

Various terminologies are often used in place of e-learning, for instance, online learning, virtual learning, distributed learning, network, or web-based learning. Whatever the terminology used, the primary connotation is the application of ICT tools, including the internet to mediate asynchronous as well as synchronous teaching and learning activities (Naidu, 2006). Instruction over the internet is perceived by many education scholars to be a significant breakthrough in teaching and learning, particularly at the institutions of higher learning (Keller \& Cernerud, 2002; Abbad, Morris \& Nahlik, 2009). Being a mode that is internet-driven, the stability and reliability of internet connectivity is a crucial part of infrastructural requirement for the adoption of e-learning.

E-learning has four distinct modalities, namely, individualized self-paced online, individualized self-paced offline, group-based synchronously, and group-based asynchronously (Romiszowski, 2004; Naidu, 2006). Under the individualized self-paced online modality, a learner accesses learning resources through the internet or intranet. The modality is appropriate for learners in contexts where internet infrastructure is reliable. A typical example is a learner studying alone or conducting some research through the internet or a local network (Naidu, 2006). Contrastingly, the individualized self-paced offline modality refers to situations where an individual learner accesses learning resources without connection to the internet or intranet. The modality is suited for learners in contexts where internet infrastructure is unreliable or non-existent, with an example being a learner working alone off a hard drive, a CD or DVD (Romiszowski, 2004; Naidu, 2006).

The group-based synchronously modality reflects a situation where groups of learners work together in real time via the internet or intranet, for instance, through videoconferencing. The synchronous mode is appropriate within contexts where internet is stable. It may include text-based conferencing, and one or two-way audio and videoconferencing. Examples of this include learners engaged in a real-time chat or an audio-videoconference (Naidu, 2006). The group-based asynchronously modality refers to a situation where groups of learners work over the internet or intranet but where feedback occurs later, for instance, communication through electronic mail (Romiszowski, 2004; Naidu, 2006). The asynchronous mode is commonly applied in countries, where the internet infrastructure is too weak or unreliable. Typical examples of this kind of activity include on-line discussions via electronic mailing lists and text-based conferencing within learning management systems (Romiszowski, 2004; Naidu, 2006).

The growing interest in e-learning seems to be coming from several directions. Firstly, institutions of higher learning that have traditionally offered distance education perceive e-learning as a logical extension of 
their distance education activities. Such institutions also consider e-learning as an avenue for improving access to and expanding the market base for their academic programs (Rosenberg, 2001), while the corporate sector views e-learning as a cost-effective way for staff training and development (D. Oblinger \& J. Oblinger, 2005; Naidu, 2006). As noted by Kihara (2005), e-learning is fast becoming the ideal mode of university education in this age of knowledge-based economies and globalization. To remain relevant, universities all over the world will have to redefine their mission and review their curriculum to integrate the use of technology. Similarly, Dunn (2000) asserted that the integration of e-learning is inevitable for institutions of higher learning that wish to remain relevant in the era of technology, while Volery (2000) emphasized the importance of e-learning to the future relevance and survival of universities across the globe.

Despite a high level of interest in e-learning, its integration in developing countries is constrained by various factors including inadequate institutional support in terms of training and financing. The transition from traditional modes of delivery to e-learning comes with various changes and challenges for lecturers, which require them to make certain adjustments in terms of mindset, attitude, and skills. In view of this, establishing a training program for lecturers remains a key component of preparedness for e-learning (Gulbahar, 2005; Inglis Ling, \& Loosten, 2000; Neil, 2004). Lecturers require a wide range of ICT skills to effectively develop courses, upload lessons, and moderate and evaluate learners (Gulbahar, 2005). This implies that academic institutions should have well-developed training programs to address skill gaps among lecturers (US Department of Education, 2000; Neil, 2004). More importantly, lecturers need to understand new pedagogy for e-learning that is the most effective practice for teaching within an e-learning environment (Inglis et al., 2000).

Saekow and Samson (2011) assessed e-learning readiness among Thai and United States (US) universities. The study noted that all the 11 universities covered in Thailand had ICT training programs in place. However, slightly more than one-half of the participants (52\%) reported that the programs were inactive, hence, they had not benefitted most members of the academia. The study also found a significant relationship between the activeness of ICT training programs and lecturers' self-perception of competence in working with computers. The study further noted that failure of some lecturers to appreciate and warm up to e-learning was one of the key factors that delayed the integration of e-learning. Besides, most training programs were not effective in helping lecturers to improve their skills, particularly due to lack of appropriate strategies and funding. Among the US universities, the study noted that lecturers were relatively more skilled in the application of e-learning tools. Besides, university authorities have initiated various non-monetary strategies to incentivize lecturers, including annual awards as well as mentorship and professional development opportunities.

A study conducted by Lion and Start (2010) reported that up to 65\% of the lecturers preferred traditional lecture mode over technology-aided modes to achieve learning outcomes. The study identified perceived incompatibility with online pedagogies, compensation issues, inadequate training, time required to create online courses, and lack of administrative support as the key factors fuelling lecturers' resistance against e-learning. People always perceive change to a new system as a threat to their status. The change process is ridden with suspicion and anxiety; without proper management of the change process, very little can be achieved. Training is key to effective management of suspicion and anxiety associated with the change process. In Botswana, Thurab-Nkhosi, Lee, and Gachago (2005) found that although the University of Botswana e-learning (UBeL) initiative's course development process was collaborative, the Educational Technology Unit (EduTech) experienced a number of challenges, including lecturer's unwillingness to participate in instructional design training. Some lecturers viewed the instructional design process as unnecessary and time-consuming. Although 
the e-learning training courses were widely publicized, participation was low, as only 28 out of 760 lecturers registered for e-learning training courses (Thurab-Nkhosi et al., 2005).

To address this challenge, Edu-Tech has worked in collaboration with the Teaching and Learning Unit (TLU) to build the capacity of academic staff and to emphasize the importance of using a systematic instructional design approach. In addition to seven pilot courses, TLU offered modified e-learning workshops to new faculty members during their orientation to teaching, research, and service at the University. The workshops have been established in conjunction with the Center for Academic Development (CAD) and certificates provided as an incentive for lecturers to improve their skills, knowledge, and attitudes towards the use of ICTs in teaching and learning. Lecturers are required to complete at least eight of the 17 workshops, with mandatory units being principles of e-learning course design; introduction to e-learning; teaching in the SMART classroom and video conferencing; information and computer skills; management techniques; online information gathering and copyright on the www; multimedia production, and WebCT refreshers (Thurab-Nkhosi et al., 2005).

The study also found that the strategy of using workshops as part of a certificate course has achieved great success with 48 lecturers awarded with certificates between 2003 and 2005. Besides, the number of lecturers attending the workshops has increased from 96 in 2002 to 221 in 2003 and 207 by June 2004. In addition, the average attendance of workshops increased from 8.5 in 2003 to 13.6 in 2004, while the average number of workshops that each lecturer attended rose from 3.4 in 2003 to 4.6 in 2004 (Thurab-Nkhosi et al., 2005). Agboola (2005) assessed the awareness and perceptions of academic staff in using e-learning tools for instructional delivery at the International Islamic University in Malaysia. The study found that training lecturers was the most important factor explaining $7.4 \%$ of variance in e-learning adoption and readiness, with the regression model explaining up to $34 \%$ of the total variance in e-learning adoption and $32 \%$ of the total variance in e-learning readiness. In view of this, Agboola (2005) noted that training and confidence building regarding the application of ICT tools are critical for enhancing lecturers' preparedness for e-learning.

Appropriate training programs are necessary because e-learning brings a number of changes in the roles of lecturers, regarding time, place and pace of lesson delivery. The transition to e-learning in universities prompts changes such as chart rooms replacing lecture halls and electronic discussions boards replacing black boards, which necessitate the mastery of new skills and competencies (Lu, Liu, \& Liao, 2005; Naidu, 2006). In the absence of training programs, transition from the traditional mode of course delivery to e-learning is often constrained by inadequate computing competence among lecturers (Farahani, 2003; Ya'acob, 2005), which is a key attribute of many institutions in developing countries, including Kenya (Omwenga, 2004; Kihara, 2005). Computing competence is the ability to use a wide range of computer applications with minimal effort and constraints, to achieve a particular purpose. A high level of computing excellence is necessary for effective use of computers in an e-learning environment (Van Braak, 2004). According to Albirini (2006), computing competence refers to user's beliefs about their computer skills and it forms a key component of institutional preparedness for e-learning.

Furthermore, e-learning is a costly undertaking that requires concrete financing plans (Schifter, 2000; Pelgrum, 2001). Due to this reason, most institutions of higher learning find it difficult to finance e-learning projects single-handedly. Again, this explains why the integration of e-learning in Africa and other developing regions lags behind compared to the status of e-learning adoption in the United States or Western Europe (Hjeltnes \& Hansson, 2005). Financial planning for e-learning projects must never overlook the issue of funding 
reliability and sustainability (Clark \& Berge, 2005). Financial planning should also include a clear system for monitoring and evaluation to enhance efficiency as well as ensure accountability and that lessons are applied to similar projects (Breitner \& Hoppe, 2005; Hjeltnes \& Hansson, 2005).

E-learning projects have significant start-up as well as operational costs. Start-up costs include the purchase of computers, internet infrastructure, software applications used to create the online presence, as well as develop and transmit course materials. Most importantly, start-up costs include the purchase of the Learning Management Systems (LMS), Learning Content Management System (LCMS), and authorizing software (Haney, 2008). Other costs include software maintenance, software licenses required to run the applications such as SQL server, cold fusion, and crystal reports among others. Start-up costs also include training of academic, technical, and administrative staff on about three or four different software applications (Hjeltnes \& Hansson, 2005; Haney, 2008).

Financial resource is critical for successful integration of e-learning at the institutions of higher learning, which in turn, has attracted empirical studies in various countries. In Syria, for instance, Albirini (2006) reported that inadequacy of financial resource to initiate and maintain ICT systems was a key factor influencing the adoption of e-learning. The study found a significant relationship between the amount allocated for ICT development and the number of computers accessible to lecturers in each department. Gulbahar (2005) also reported that inadequate financial provisions played a crucial role in influencing the integration of e-learning projects in Singaporean universities. In this regard, public universities differed significantly based on the amount of funds allocated for ICT development. The study reported that budgetary allocation accounted for $4.6 \%$ of variance in the proportion of lecturers consistently using computers and $3.9 \%$ of variance in lecturers' perception of preparedness for e-learning.

Similar findings are also evident in the works of Schifter (2000), who noted that lack of funds for materials and expenses influenced the rate of integration and utilization of Asynchronous Learning Networks (ALNs). According to Pelgrum (2001), e-learning is a capital-intensive undertaking, which most institutions cannot finance single-handedly, hence, its successful integration largely depends on the funding strategies and models adopted by an institution. Reaching out to the government and the corporate sector for funding support is one of the models often documented for e-learning universities in developed countries (Pelgrum, 2001). Institutional financial management policies also remain critical for the success of e-learning projects, as noted by Pelgrum (2001), Bates (1997), and Biggs (1999). Institutions with devolved financial management systems are more likely to sustain e-learning projects at the faculty level, than institutions whose financial systems are centralized. Besides, financial management policies should emphasize a multi-pronged approach to resource mobilization through internal and external sources (Dibiase, 2000).

Due to prohibitive establishment and operational costs, the integration of e-learning in developing countries is constrained by inadequacy of necessary workplace infrastructure, including access to computers, reliability of internet connectivity and access to ICT technical support. According to Ngai, Poon, and Chan (2007), the fundamental obstacle to the growth of e-learning is lack of access to necessary technological workplace infrastructure. Poor or insufficient infrastructure may restrict access to ICT facilities by lecturers, learners, and administrators.

Similarly, limited access to ICT infrastructure is likely to impair practice, efficiency, and effectiveness of e-learning initiatives. Also crucial is the cost of system support and maintenance, as well as the appropriate training of staff to enable them to make the most of technology (Ngai et al., 2007). Studies conducted by Hitt 
and Hartman (2002), Gulbahar (2005), and Albirini (2006) suggest that preparedness for e-learning significantly associates with access to functional computers at the workplace, which often influences the proportion of lecturers using computers to support delivery of their lessons. Accordingly, institutional leadership should aggressively pursue collaborative partnerships to raise supplementary resources to finance the transition from traditional modes of delivery to e-learning, not only in terms of necessary infrastructure but also in the development of human resource for technical backing (Dibiase, 2000; Naidu, 2006).

The influence of institutional support on lecturers' preparedness for e-learning has attracted empirical investigations in various socio-economic and cultural contexts. However, no comprehensive documentation of the subject has been done in Kenya, leading to shortage of academic literature to inform policy processes and programming. Although the University of Nairobi has been a leading icon in Open and Distance Learning (ODL) activities within the East African region, e-learning is still at the early stages of development. Transition from the traditional mode to e-learning is constrained by factors such as lack of appropriate training and financing programs, which in turn, affects lecturers' computing competence as well as access to necessary workplace infrastructure, including computers, internet, and technical support (Kariuki, 2006). The purpose of this study was to assess the existence and functionality of appropriate training program for e-learning and the level of financing at the University of Nairobi, from lecturers' perspective.

\section{Methodology}

This study was founded on the positivist philosophy of social research, holding that in social sciences, information derived from sensory experience is the exclusive source of all authoritative knowledge. Besides, the world is external and objective, and that the observer is independent of the phenomena being observed. The positivist thought assumes that valid knowledge can only be found in scientific knowledge (Ashley \& Orenstein, 2005). Based on the positivistic thinking, a cross-sectional survey design with both quantitative and qualitative approaches was applied to guide the research process (Babbie, 1973; Fowler, 1993). Whereas, the quantitative approach elicited information used for descriptive and inferential purposes using self-administered questionnaires, the qualitative approach obtained in-depth information through key informant interviews.

Primary data was collected in May 2011 from lecturers and administrative staff at the University of Nairobi. Although the study focused on lecturers' preparedness for e-learning, the inclusion of administrative staff was based on their crucial role in policy formulation, implementation, and enforcement, which influence the work environment in which lecturers operate. Their inclusion in the study was purposed to identify policy gaps regarding ICT strategies, plans, budgetary allocations, and ICT development, which are likely to influence lecturers' preparedness to function in an e-learning environment. Unpublished data from the office of Deputy Vice Chancellor, Finance and Administration showed that the University had 958 academic and 108 administrative staff at the time of the study.

With a finite population of lecturers, one of Fisher's formulae for sample size determination was applied to obtain a sample size of 213 participants. Stratified random sampling was applied to select the lecturers, with the stratification being based on colleges, gender, and cadre. This ensured proportionate representation of all colleges; male and female lecturers; as well as assistant lecturers, lecturers, senior lecturers, associate professors, and professors. Proportionate samples from each stratum were obtained by first, calculating the sampling fraction, as a quotient of the sample size $\left(n_{i}\right)$ and the population $\left(N_{i}\right)$. Table 1 shows the proportionate sample sizes from each college. 
Table 1

Proportionate Samples of Academic Staff for Each College

\begin{tabular}{lcc}
\hline Colleges & Sampling frame & Sample size \\
\hline Humanities and Social Sciences & 412 & 92 \\
Biological and Physical Sciences & 170 & 38 \\
Health Sciences & 52 & 12 \\
Education and External Studies & 125 & 28 \\
Agriculture and Veterinary Sciences & 94 & 21 \\
Architecture and Engineering & 105 & 23 \\
Total & $\mathbf{9 5 8}$ & $\mathbf{2 1 3}$ \\
\hline
\end{tabular}

From each stratum, simple random sampling was applied to select respondents. In addition, purposive sampling procedure was applied to select administrative staff, based on their availability and accessibility at the time of the study. The sample included six principals, six deputy principals, six registrars, 21 assistant registrars, 20 deans and directors, 13 associate deans and deputy directors, as well as 36 administrative assistants. Three sets of instruments, including a self-administered survey questionnaire for lecturers, a key informant interview schedule for administrators, and an observation schedule were used to source the data. The tools were pretested on 20 lecturers and 10 administrators, which were equivalent to about $10 \%$ of the computed sample sizes for each category. Data was obtained by issuing questionnaires to lecturers, which were collected after two weeks. Administrators were interviewed at their places of work; the investigator sought informed consent from each participant. In this regard, participants were briefed about the study, purpose, potential benefits and that participation was on voluntary terms.

Both quantitative and qualitative techniques were applied to process and analyze. Quantitative data were analyzed at three levels, namely univariate, bivariate, and multivariate. Univariate analysis yielded frequency distributions and percentages and bivariate analysis obtained cross tabulations with Chi-square $\left(x^{2}\right)$ tests. All the quantitative analyses were performed using the Statistical Package for Social Sciences (SPSS) and Ms-Excel packages. In addition, qualitative data were organized and summarized in line with the thematic areas; described to produce summary sheets, and followed by systematic analysis and interpretation. Details about the methods applied in this study have been described in various publications, including Babbie (1973), Fowler (1993), Aldrich and Nelson (1984), C. F. Nachmias and D. Nachmias (1996), O. M. Mugenda and A. G. Mugenda (1999), Wuensch (2006), as well as Best and Khan (2004).

\section{Results}

The study covered 212 lecturers and 96 administrative staff. The lecturers were draw from all the colleges of the University, including 104 (49.1\%) from the College of Humanities and Social Sciences (CHSS), 19 (9.0\%) from the College of Biological and Physical Sciences (CBPS), 24 (11.3\%) from the College of Health Sciences (CHS), 29 (13.7\%) from the College of Education and External Studies (CEES), 20 (9.44\%) from the College of Agriculture and Veterinary Sciences (CAVS), and 16 (7.5\%) from the College of Architecture and Engineering (CAE). In terms of gender, the lecturers included $146(68.9 \%)$ men and $66(31.1 \%)$ women. The 96 administrative staff included 34 (35.4\%) administrative assistants, $6(6.3 \%)$ college registrars and $15(15.6 \%)$ assistant registrars; $10(10.4 \%)$ departmental chairpersons; $10(10.4 \%)$ faculty deans and $6(6.3 \%)$ associate deans; as well as $8(8.3 \%)$ directors and $7(7.3 \%)$ deputy directors. In addition, the administrative staff included $64(66.7 \%)$ men and $32(33.3 \%)$ women. 


\section{E-learning Preparedness}

Lecturers' preparedness for e-learning was measured in terms of perceived computing competence, referring to the ability to execute commands and manipulate a range of software applications for various purposes. In this regard, participants were requested to rate their competence on each of the following computing software tools on a scale of 1-10: word processing, spreadsheets, presentation, statistical analysis, internet browsing, and e-mailing. The participants' ratings for each software tool were summed and mean scores determined. Resultant quotients were then rated on a scale of $0 \%-49 \%$ and $50 \%-100 \%$. Participants whose mean scores were less than $50 \%$ were considered to be below average, thus, they were likely to be unprepared to function in an eLearning environment. Conversely, those whose mean scores were above 50\% were considered to above average and likely to be prepared for e-learning. Based on the principle, out of 212 participants, $103(48.6 \%)$ had a mean score of 50\% or higher; while 109 (51.4\%) scored less than 50\%, suggesting that slightly more than one-half of the lecturers were below average in terms of computing competence.

\section{E-learning Preparedness and Lecturers' Background Profile}

The results presented in Table 2 show that out of 212 participants, 97 (45.8\%) were in the 40 to 49 years age bracket, $4(25.5 \%)$ were aged between 50 and 59 years, while $22(10.8 \%)$ were in the 30 to 39 years bracket. Besides, another $22(10.8 \%)$ reported to be 60 years or higher, while $8(3.9 \%)$ were aged below 30 years. Table 2 further shows that the proportion of lecturers unprepared for e-learning in the 50+ age category was more than that of those prepared in the same age category. Conversely, the proportion of staff prepared for e-learning aged below 40 years was higher than the proportion of those unprepared. The pattern suggests that younger academic staff were likely to be more competent in working with software tools; hence, they were likely to be better prepared for e-learning than their relatively older colleagues.

Based on this, bivariate analysis obtained a computed Chi-square $\left(x^{2}\right)$ value of 18.026 , with four degrees of freedom and a $p$-value of 0.001 , which is significant at 0.01 error margin, suggesting up to $99 \%$ chance that lecturers' preparedness for e-learning significantly associated with age. Similar findings on the link between age and computing competence were reported by Venkatesh and Morris (2000) who assessed the role of gender and social influence on technology acceptance behaviour among academic staff of Indian public universities. The study found that younger lecturers were more receptive to new technologies than their older counterparts. In Jordan, Abbad et al. (2009) found a negative correlation between lecturers' age and e-learning delivery methods.

Table 2 further shows that $146(68.9 \%)$ participants were men and $66(31.1 \%)$ were women and that the proportion, $34(33.0 \%)$, of women lecturers prepared for e-learning was marginally higher than the proportion of those unprepared, 32 (29.4\%). However, the proportion of men, 69 (67.0\%), prepared for e-learning was lower than the proportion of those unprepared, 77 (70.6\%). The analysis revealed lack of a significant relationship between lecturers' gender and preparedness for e-learning (computed $x^{2}=1.039$ (corrected for continuity), $d f=1$, and $p$-value $=0.243$ ), suggesting that no gender was more competent in computing than the other; hence, none was likely to be more prepared than the other. This is however, inconsistent with the findings of Luan et al. (2005), who noted that female and male academicians were significantly different in the application of software packages such as word processing, spreadsheets, and presentation tools. However, in Egypt, Houtz and Gupta (2001) found that male lecturers were more confident and had a greater usage of computers compared to their female counterparts. 
Table 2

Background Profile and Preparedness for E-learning

\begin{tabular}{|c|c|c|c|c|c|c|}
\hline \multirow{2}{*}{ Background attributes } & \multicolumn{2}{|c|}{ Prepared } & \multicolumn{2}{|c|}{ Unprepared } & \multicolumn{2}{|c|}{ Total } \\
\hline & Frequency & Percent & Frequency & Percent & Frequency & Percent \\
\hline \multicolumn{7}{|l|}{ Age } \\
\hline$<30 \mathrm{yrs}$ & 8 & 8.3 & 0 & 0.0 & 8 & 3.9 \\
\hline $30-39$ yrs & 12 & 12.5 & 10 & 9.3 & 22 & 10.8 \\
\hline $40-49$ yrs & 45 & 46.9 & 52 & 48.6 & 97 & 47.8 \\
\hline $50-59$ yrs & 23 & 24.0 & 31 & 29.0 & 54 & 26.7 \\
\hline $60+$ yrs & 8 & 8.3 & 14 & 13.1 & 22 & 10.8 \\
\hline Total & 96 & 100.0 & 107 & 100.0 & 203 & 100.0 \\
\hline \multicolumn{7}{|l|}{ Gender } \\
\hline Male & 69 & 67.0 & 77 & 70.6 & 146 & 68.9 \\
\hline Female & 34 & 33.0 & 32 & 29.4 & 66 & 31.1 \\
\hline Total & 103 & 100.0 & 109 & 100.0 & 212 & 100.0 \\
\hline \multicolumn{7}{|l|}{ Education level } \\
\hline Bachelors & 1 & 1.0 & 4 & 3.7 & 5 & 2.4 \\
\hline Masters & 36 & 35.0 & 20 & 18.3 & 56 & 26.4 \\
\hline Ph.D. & 66 & 64.0 & 85 & 78.0 & 151 & 71.2 \\
\hline Total & 103 & 100.0 & 109 & 100 & 212 & 100.0 \\
\hline \multicolumn{7}{|l|}{ Average monthly income } \\
\hline$<$ KES 50,000 & 4 & 3.9 & 0 & 0.0 & 4 & 1.8 \\
\hline KES 50,000-59,000 & 0 & 0.0 & 3 & 2.8 & 3 & 1.4 \\
\hline KES $60,000-69,000$ & 7 & 6.8 & 4 & 3.7 & 11 & 5.2 \\
\hline KES 70,000-79,000 & 10 & 9.7 & 7 & 6.5 & 17 & 8.1 \\
\hline KES $80,000-89,000$ & 9 & 8.7 & 12 & 11.1 & 21 & 10.0 \\
\hline KES 90,000+ & 73 & 70.9 & 82 & 75.9 & 155 & 73.5 \\
\hline Total & 103 & 100.0 & 108 & 100.0 & 211 & 100.0 \\
\hline
\end{tabular}

The results show that up to 151 (71.2\%) lecturers reported holding Ph.D. degrees, 56 (26.4\%) held masters certificates, while 5 (2.4\%) had bachelor's degree qualifications. Besides, Table 2 indicates that the proportion of Ph.D. holders unprepared for e-learning was higher than that of those prepared. Conversely, the proportion of masters' degree holders prepared for e-learning was higher than that of those unprepared. Based on this pattern, a computed Chi-square $\left(x^{2}\right)$ value of 11.031 was obtained, with 2 degrees of freedom and $p$-value of 0.004 , which is significant at 0.01 error margin, suggesting up to $99 \%$ chance that lecturers' preparedness for e-learning significantly associated with educational attainment. Thus, masters' degree holders, being relatively younger people, were likely to be more competent in computing, hence, they are better prepared for e-learning than Ph.D. holders. These findings are consistent with those reported by Roberts, Hutchinson, and Little (2003) who assessed barriers to the use of technology for teaching among Dutch universities. The study noted that professors and associate professors were less likely to use ICT tools in their teaching than junior lecturers.

Table 2 further indicates that most participants, 155 (73.1\%) were earning KES 90,000 or more, 21 (9.9\%) were in the KES 80,000 to 89,000 bracket, 17 (8.0\%) averaged at between KES 70,000 and 79,000, while 11 (5.2\%) reported an income of KES 60,000 to 69,000. In addition, the proportion of lecturers unprepared for e-learning in the top income bracket was higher than the proportion of those prepared. Contrastingly, the proportion prepared for e-learning in the category of less than KES 60,000 was higher than those unprepared. The analysis yielded a computed Chi-square $\left(x^{2}\right)$ value of 11.707 , with 5 degrees of freedom and $p$-value of 
0.039 , which is significant at 0.05 error margin, suggesting up to $95 \%$ chance that preparedness for e-learning varied significantly across the income categories. Similarly, Venkatesh and Morris (2000) found a positive correlation between the frequency of computer use and lecturers' average income. The study noted that although lecturers in higher income brackets had a greater access to personal computers than those in lower income scales, more than one-half did not use computers consistently to support their work due to limited ICT skills.

\section{Staff ICT Training Program}

Lecturers were requested to indicate knowledge of whether the university had in place an ICT training program for academic staff or not. As indicated in Table 3, up to 90 (42.5\%) participants affirmed that the university had a training program, however, $81(38.2 \%)$ stated that such program was non-existent, while 41 (19.3\%) did not know whether it was in place or not. In addition, the results show that most of those, 49 (47.6\%), prepared for e e-learning were aware of the ICT training program, while most of those unprepared, 48 $(44.1 \%)$, indicated that such program was non-existent.

Based on these results, the cross tabulation analysis obtained a computed Chi-square $\left(x^{2}\right)$ value of 3.346, with 2 degrees of freedom and a $p$-value of 0.188 , which is not significant, suggesting lack of significant relationship between lecturer's preparedness for e-learning and knowledge of the existence of an ICT training program for academic staff. Those who were aware and those not aware that a training program exists were not significantly different in terms of computing competence and preparedness for e-learning. In relation to this finding, administrative staff pointed out that although the program had been initiated, it was still young in terms of funding and strategies; consequently, most departments were yet to be reached with ICT training in preparation for e-learning.

Table 3

Availability and Effectiveness of ICT Training Program

\begin{tabular}{|c|c|c|c|c|c|c|}
\hline \multirow{2}{*}{$\begin{array}{l}\text { Availability and effectiveness } \\
\text { of the training program }\end{array}$} & \multicolumn{2}{|c|}{ Prepared } & \multicolumn{2}{|c|}{ Unprepared } & \multicolumn{2}{|c|}{ Total } \\
\hline & Frequency & Percent & Frequency & Percent & Frequency & Percent \\
\hline \multicolumn{7}{|c|}{$\begin{array}{l}\text { University has an ICT training } \\
\text { program for lecturers? }\end{array}$} \\
\hline Yes & 49 & 47.6 & 41 & 37.6 & 90 & 42.5 \\
\hline No & 33 & 32.0 & 48 & 44.1 & 81 & 38.2 \\
\hline Don't know & 21 & 20.4 & 20 & 18.3 & 41 & 19.3 \\
\hline Total & 103 & 100.0 & 109 & 100.0 & 212 & 100.0 \\
\hline \multicolumn{7}{|l|}{$\begin{array}{l}\text { Effectiveness of the ICT } \\
\text { training program for lecturers }\end{array}$} \\
\hline Very effective & 2 & 4.1 & 2 & 4.9 & 4 & 4.4 \\
\hline Effective & 32 & 65.3 & 26 & 63.4 & 58 & 64.5 \\
\hline Ineffective & 15 & 30.6 & 13 & 31.7 & 28 & 31.1 \\
\hline Total & 49 & 100.0 & 41 & 100.0 & 90 & 100.0 \\
\hline
\end{tabular}

The results in Table 3 further show that 58 (64.5\%) participants affirming the existence of ICT training program believed that it was "effective" in improving computing competence among academic staff, another 28 $(31.1 \%)$ hinted that the program was "ineffective", while $4(4.4 \%)$ felt that it was "very effective". In connection to this, the results show lack of significant variation between those prepared and those unprepared for e-learning regarding perception on the effectiveness of the training program for academic staff. In this 
regard, the analysis yielded computed Chi-square $\left(x^{2}\right)$ value of 0.053 , with 2 degrees of freedom and a $p$-value of 0.974 , which was not significant. Thus, the perceived effectiveness of the training program was less likely to influence lecturers' preparedness for e-learning. Consequently, the null hypothesis $\left(\mathrm{H}_{0} 1\right)$, stating that the effectiveness of ICT training program has no significant relationship with lecturers' preparedness for e-learning, was not rejected for inadequacy of empirical evidence.

The results show that lecturers had accessed training in various software tools, including word processing, 156 (73.6\%); spreadsheets, 119 (56.1\%); presentation, 135 (63.7\%); statistical analysis, 102 (48.1\%); internet browsing, 127 (59.9\%); and e-mailing, 107 (50.5\%). The analysis showed that lecturers' preparedness for e-learning is significantly associated with training in word processing, presentation, internet browsing, spreadsheets, and statistical analysis. The results amplify the importance of training in software tools, thus, participants who reported having some training were better prepared for e-learning than those who had not trained.

Furthermore, the duration of training for word processing tools averaged at 3.3 weeks (95\% CI 2.3-4.4), presentation tools averaged at 2.0 weeks (95\% CI 1.1-2.9), while the training for internet browsing averaged at 1.7 weeks (95\% CI 0.9-2.5). More still, mean duration of training for spreadsheets tools was 2.4 weeks (95\% CI 1.2-3.6), statistical analysis tools were 2.2 weeks (95\% CI weeks (95\% CI 0.5-4.0), and e-mailing was 2.04 weeks (95\% CI 0.9-3.2). The results show that mean duration of training in word processing tools was the longest at 3.3 weeks, while the shortest training duration was in internet browsing at 1.7 weeks. Although there was no significant variation in the duration of training across the software tools, the common denominator is that the trainings were too short and barely matched the scope of software programs such as Microsoft Word, Microsoft Excel, and statistical analysis tools.

Most lecturers, 108 (69.2\%), sponsored themselves for training in word processing tools and only 40 $(25.6 \%)$ were sponsored by the employer (University of Nairobi). For spreadsheet tools, up to 84 (70.6\%) participants sponsored themselves, while $29(24.4 \%)$ were sponsored by the employer. In the case of presentation tools, $102(75.6 \%)$ sponsored themselves, while 28 (20.7\%) had been facilitated by the employer. The pattern was similar for training in statistical analysis, internet, and e-mailing tools. Among the self-sponsored trainees, the proportion of participants unprepared for e-learning was higher than the proportion prepared; contrastingly, among those sponsored by the University, the proportion of those prepared for e-learning was higher. This suggests that training facilitated by the employer was likely to be more intensive than the training acquired through self-sponsorship.

Key informants revealed that the university had established a team of ICT experts, based on the School of Computing and Informatics, to help academic staff understand e-learning, its importance in higher education, and its applicability in transforming courses from paper to digitalized form. However, the team had not achieved much discharging its mandate due to funding constraints and involvement in administrative as well as academic work. Besides, key informant interviews suggested that support for lecturers to enhance their computing skills may be improved through various actions, including creating partnerships with public and private sector organizations specializing in ICT, with a view to creating avenue for sharing information and other resources such as e-learning and teaching programs.

These findings are in line with those reported by Saekow and Samson (2011) who noted that although most Thai Universities had established training programs to help lecturers improve their skills and to develop positive attitude towards e-learning, most lecturers failed to warm up with the project. The main constraints 
included lack of appropriate strategies and funding challenges. Consequently, the study emphasised the need for ICT training programs targeting university lecturers to be revamped with resources to enable academic staff understand and appreciate the importance of e-learning mode.

\section{Annual Budgetary Allocation}

The amount of funds allocated for the development of ICT competence among lecturers is an important ingredient for enhancing lecturers' preparedness to function in an e-learning environment. In view of this, participants were asked to indicate their perception about the amount of resources allocated by the university to support the development of ICT infrastructure and skills among academic staff in their departments, schools, or centres. In this regard, only 51 (24.1\%) believed that the resources allocated were adequate, $76(35.8 \%)$ felt that budgetary allocations were inadequate, while the majority 85 (40.1\%) did not know whether the allocations were adequate or not. Key informants observed that although sharing information about budgetary allocation with staff members was a good management practice; this was not always the case at the University of Nairobi. Consequently, a significant proportion of lecturers was not aware of ICT development budgets and programs. Besides, Table 4 confirms that with a significant proportion of participants, 80 (40.1\%) did not know anything about budgetary allocation for ICT development, regardless of the perceived preparedness for e-learning.

Table 4

Adequacy of Resources Allocated to Develop ICT Program

\begin{tabular}{lcccccc}
\hline $\begin{array}{l}\text { Perceived adequacy of } \\
\text { budgetary allocations }\end{array}$ & \multicolumn{2}{c}{ Prepared } & \multicolumn{2}{c}{ Unprepared } & \multicolumn{2}{c}{ Total } \\
\cline { 2 - 7 } Allocation for developing & Frequency & Percent & Frequency & Percent & Frequency & Percent \\
ICT program adequate? & & & & & & \\
Yes & 33 & 32.0 & 18 & 16.5 & 51 & 24.1 \\
No & 34 & 33.0 & 42 & 38.5 & 76 & 35.8 \\
Don't know & 36 & 35.0 & 49 & 45.0 & 85 & 40.1 \\
Total & 103 & 100.0 & 109 & 100.0 & 212 & 100.0 \\
How adequate? & & & & & \\
Very adequate & 15 & 22.4 & 4 & 6.7 & 19 & 15.0 \\
Adequate & 21 & 31.3 & 18 & 30.0 & 39 & 30.6 \\
Inadequate & 22 & 32.8 & 21 & 35.0 & 43 & 33.9 \\
Very inadequate & 9 & 13.5 & 17 & 28.3 & 26 & 20.5 \\
Total & 67 & 100.0 & 60 & 100.0 & 127 & 100.0 \\
\hline
\end{tabular}

Cumulatively, up to $69(54.4 \%)$ believed that budgetary allocation was either inadequate or very inadequate; this included 31 (46.3\%) participants who were prepared and 38 (63.3\%) who were unprepared for e-learning. In this regard, the analysis obtained a computed Chi-square $\left(x^{2}\right)$ value of 8.725 , with 3 degrees of freedom and a $p$-value of 0.033 , which was significant at 0.05 error margin, suggesting up to $95 \%$ chance that lecturer's preparedness for e-learning significantly is associated with the perceived adequacy of budgetary allocation for ICT program at the departmental level. Consequently, budgetary allocation was likely to influence preparedness for e-learning; thus, the null hypothesis $\left(\mathrm{H}_{0} 2\right)$, stating that the relationship between annual budgetary allocation for ICT and lecturers' preparedness for e-learning is not statistically significant, was rejected for being untrue.

The findings reveal that the e-learning program at the University of Nairobi has not been well-funded. The study conducted by Albirini (2006) revealed that inadequacy of financial resource to initiate and maintain 
systems was one of the factors influencing the integration and use of e-learning in academic institutions. Similarly, Gulbahar (2005) also reported that inadequate financial provisions played a crucial role in influencing institutional use of e-learning in Singaporean universities. It is critical to note that e-learning is a capital-intensive program that requires proper preparation in terms of financial resources. For this reason, key informants reiterated the need to improve budgetary allocation for ICT development in all departments of the University to ensure that all lecturers gain access to functional computers at the workplace, reliable internet connectivity, and timely technical support.

Out of 212 lecturers, 194 (91.5\%) had access to functional computers at their workplace, only 18 (8.5\%) did not. The proportion of staff prepared for e-learning was higher among those who had access to computers at the workplace, 99 (96.1\%), than among those who did not, 95 (87.2\%). Bivariate analysis revealed a significant relationship between lecturers' preparedness for e-learning and access to functional computers at the workplace [computed $x^{2}$ value $=9.380$ (corrected for continuity), $d f=1$, and $p$-value $=0.036$ ]. This suggests that participants having access to computers at the workplace were likely to be more competent in computing, thus they were better prepared to function in an e-learning environment than those lacking such access.

Although up to $91.5 \%$ of the participants reported having access to computers at the workplace, about two-thirds were using personal computers as those provided by the university were inadequate. Access to computers at the workplace provides opportunity for practice and skill improvement, which in turn, discourages anxiety and negative attitudes that may be associated with computer use. Access to computers at the workplace has been assessed by various scholars, including Albirini (2006), Gulbahar (2005), and Blankenship (1998). For instance, a study conducted by Albirini (2006) in Syria found that only 33\% of the lecturers had access to computers at their places of work, which in turn, influenced the proportion using computers to support teaching activities. The study also indicated that the adequacy of appropriate computers was a key factor influencing lecturers' preparedness to operate in an e-learning environment.

Even though the University of Nairobi had initiated a program intended to provide computers to each lecturer, key informants revealed that it was still in its infancy stage, as many departments were yet to realize universal access to modern and efficient computers. Regarding the quality of computers, the results show that most workplace computers were of the Pentium IV generation, which was among the latest models at the time of the study. In this regard, 41 (27.0\%) participants indicated that their computers were in "excellent condition" and $56(36.8 \%)$ stated condition to be "good". However, 43 (28.3\%) respondents noted that the condition was "poor", while $12(7.9 \%)$ described it as "very poor". The results further revealed lack of significant association between lecturer's preparedness for e-learning and perceived quality of workplace computers.

More still, of the 194 participants having access to computers at the workplace, 185 (95.4\%) were connected to the internet. The results further show that among those having internet connection, 21 (11.3\%) indicated that it was "very reliable", while 103 (55.7\%) stated that it was "reliable". Contrastingly, 52 (28.1\%) participants hinted that Internet connectivity was "unreliable", while 9 (4.9\%) hinted that it was "very unreliable". Based on this, the analysis obtained a computed Chi-square $\left(x^{2}\right)$ value of 9.052 , with 3 degrees of freedom and a $p$-value of 0.030 , which is significant at 0.05 error margin, suggesting up to $95 \%$ chance that lecturer's preparedness for e-learning significantly associated with perceived reliability of internet connectivity. Key informants revealed that university internet was unreliable and unstable in some campuses, which demoralizes and discourages consistent use by academic staff in the affected campuses. Studies conducted in various contexts have also noted that internet reliability is critical for lecturers' preparedness for e-learning. For 
instance, Mercado (2008) reported that although a stable internet connectivity is critical requirements for e-learning, this factor remain key a challenge to the adoption of e-learning in developing countries. Slow and unreliable connectivity makes internet access too expensive and difficult to access information.

Another important dimension of budgetary support for the development of e-learning program is the timeliness of technical support for lecturers. How soon the technical team is able to respond to issues raised by lecturers is a critical determinant of positive attitude towards e-learning. Inadequacy or untimely access to technical support is likely to encourage detachment between lecturers and their ICT facilities, including computers. Similarly, Butler and Sellbom (2002) found that lack of or delay in providing technical services by the university was often stressful to lecturers, leading to low acceptance of technology for teaching. In this study, 63 (50.4\%) participants stated that the support provided was "timely", 43 (34.4\%) felt that the support was "untimely", while 12 (9.6\%) indicated that it was "very untimely". The results further indicated that 42 (68.9\%) participants who expressed satisfaction about the timeliness of technical support provided by the university were prepared for e-learning, while most of those who were unsatisfied with the timeliness of technical support 36 (56.3\%), were unprepared for e-learning. The analysis indicated up to $99 \%$ chance that lecturer's preparedness for e-learning significantly is associated with their perceptions about the timeliness of technical support provided by the university (computed $x^{2}=18.572, d f=3$, and $p$-value $=0.000$ ).

Key informants revealed that the timeliness of technical support to academic staff was unpredictable; sometimes technical staff respond to reported issues in a matter of minutes, while other times they delay for as long as a week. Besides, technical support teams seemed to be faster in responding to issues affecting departmental administrative units than to issues reported by lecturers. Participants advocated for better budgetary allocation, decentralization of ICT support centres to each department for timely response to issues affecting lecturers and recruitment of more technical support staff.

\section{Conclusions}

The objective of this study was to determine the influence of institutional support on lecturers' preparedness for e-learning, focusing on the effectiveness of the ICT training program, as well as perceived adequacy of budgetary allocation, in relation to access to computers at the workplace, reliability of internet connectivity, and timeliness of ICT technical support. The study revealed lack of significant relationship between lecturer's preparedness for e-learning and knowledge of the existence of an ICT training program for academic staff (computed $x^{2}=3.346, d f=2$, and $p$-value $=0.188$ ). Although a training program had been established, it was still at nascent stages in terms of funding and strategies; consequently, most departments were yet to be reached with training in preparation for e-learning. The study also revealed lack of significant relationship between lecturers' preparedness for e-learning and perceived effectiveness of the training program (computed $x^{2}=0.053, d f=2$, and $p$-value $=0.974$ ).

More still, lecturers' preparedness for e-learning significantly is associated with training in software tools, including word processing, presentation, internet browsing, spreadsheets, and statistical analysis. Whereas some lecturers sponsored themselves to access such training, others had benefitted from university sponsorship. Nevertheless, a higher proportion of self-sponsored lectures were unprepared for e-learning, while among those sponsored by the university, the proportion of those prepared for e-learning was higher. This suggests that training facilitated by the university was likely to be more intensive than the training acquired through self-sponsorship, suggesting the importance of an ICT training program. Although a team of ICT experts has 
been mandated to help academic staff understand e-learning, its importance in higher education, applicability, and the team's functionality was constrained by under-funding and multiple roles.

Training is the most important antecedent to lecturer's preparedness to function in an e-learning environment. A training program is essential in helping lecturers to improve their ICT skills, understand e-learning, and appreciate its value in the delivery of quality university education. Training is also necessary for attitude change in favor of e-learning, as well as allaying fears and anxiety that may be associated with the introduction of new technology. In view of this, universities in resource-poor settings should consider creating partnerships with public and private sector organizations specializing in ICT, with a view to creating avenue for sharing information and other resources such as e-learning and teaching programs. The institutions should also consider revamping existing training programs with financial and human resources to enable academic staff appreciate the importance of e-learning mode.

The study found a significant relationship between lecturer's preparedness for e-learning and perceived adequacy of budgetary allocation for ICT program at the departmental level (computed $x^{2}=8.725, d f=3$, and $p$-value $=0.033$ ). Under-funding was a key factor emerging from the study as a constraint to the adoption of e-learning at the University of Nairobi. In view of this, although up to $91.5 \%$ of the participants reported having access to computers at the workplace, about two-thirds were using personal computers as those provided by the university were inadequate. Even though the university had initiated a program intended to provide computers to each lecturer, it was constrained by under-funding; hence, many departments were yet to realize universal access to efficient computers. Besides, the institution's internet connectivity was unreliable and unstable in some campuses, thereby discouraging consistent use by lecturers. Disappointment in accessing the internet is likely to reinforce user apprehensiveness, which in turn, discourages academic staff from developing their computing skills. Participants who expressed satisfaction with the timeliness of technical support provided to lecturers were prepared for e-learning, while most of those who were dissatisfied were unprepared. Nevertheless, the timeliness of technical support to academic staff was unpredictable and skewed in favor of certain departments.

Being a capital-intensive investment, there is no doubt that implementing e-learning in an environment of resource scarcity and competing priorities may be a key challenge. This necessitates the creation of linkages with key funding institutions to support the development of e-learning programs. Universities should also consider improving budgetary allocation for ICT development in all departments to ensure universal access to functional computers at the workplace, reliable internet connectivity, and timely technical support.

\section{References}

Abbad, M., Morris, D., \& Nahlik, C. (2009). Factors affecting student and lecturer use of e-learning systems in Jordan. International Review of Research in Open and Distance Learning, 10(2), 1-22.

Agboola, A. K. (2005). Assessing the awareness and perceptions of academic staff in using e-learning tools for instructional delivery in a post-secondary institution: A case study of the International Islamic University of Malaysia. Journal of Management Information Systems, 9(1), 112-120.

Albirini, A. (2006). Teachers' attitudes toward information and communication technologies in Syrian Tertiary Institutions. Journal of Computer and Education, 47(1), 373-398.

Aldrich, S. T., \& Nelson, P. D. (1984). Advanced quantitative techniques for social sciences (2nd ed.). New York: Routledge.

Ashley, D., \& Orenstein, D. M. (2005). Sociological theory: Classical statements (6th ed.). Boston: Pearson Education.

Babbie, E. R. (1973). Survey research methods. Belmont: Wadsworth Publishing Company.

Bates, A. W. (1997). The impact of technological change on open and distance learning. Distance Education, 18(1), 93-109. 
Best, J. W., \& Khan, J. V. (2004). Research in education (7th ed.). New Delhi: Prentice Hall of India.

Biggs, J. (1999). Teaching for quality learning at university. Philadelphia: Society for Research into Higher Education and Open University Press.

Blankenship, W. (1998). Factors related to computer use by teachers in classroom instruction (Doctorate Dissertation submitted to Virginia State University).

Breitner, M. H., \& Hoppe, G. (2005). A glimpse at business models and evaluation approaches for e-learning. Heidelberg: Physica/Springer.

Butler, D. L., \& Sellbom, M. (2002). Barriers to adopting technology in teaching and learning. Educause Quarterly, 1, $22-28$.

Clark, T. \& Berge, Z. (2005). Virtual schools and e-learning: Planning for success. Retrieved from www.uwex.edu/disted/conference/

Dibiase, D. (2000). Is distance education a fautian bargain? Journal of Geography in Higher Education, 24(1), 130-136.

Dunn, S. L. (2000). The virtualization of education. Futurist, 34(1), 34-39.

Farahani, G. O. (2003). Existence and importance of online interaction (A Ph.D. dissertation submitted to the faculty of the Virginia Polytechnic Institute and State University, Virginia, USA).

Fowler, F. (1993). Survey research methods. Beverly Hills: Sage.

Gulbahar, Y. (2005). Technology planning: A roadmap to successful technology integration in schools. Journal of Computers and Education, 33(2), 324-366.

Haney, D. (2008). Assessing organisational readiness for e-learning. Performance Improvement, 41(2), $216-221$.

Hitt, C., \& Hartman, L. (2002). Distributed learning: New challenges and opportunities for institutional leadership. American Council of Education/EDUCAUSE, 25(4), 134-156.

Hjeltnes, T. A., \& Hansson, B. (2005). Cost effectiveness and cost efficiency in e-learning. European Journal of Social Sciences, 2(1), 36-45.

Houtz, S., \& Gupta, P. (2001). Gender roles, computer attitudes and dyadic computer interaction performance among university lecturers in Egypt. Journal of Organisational Behaviour, 20(3), 1-9.

Inglis, A., Ling, P., \& Loosten, V. (2000). Delivering digitally: Managing the transition to the knowledge media. London: Kogan Page.

Kariuki, J. (2006). E-learning in Kenya Universities: Random reflections about e-learning in Africa. Retrieved from http://unesdoc.unesco.org/images/0014/001419/141952e.pdf

Keller, C., \& Cernerud, L. (2002). Students' perception of e-learning in university education. Learning, Media and Technology, 27(1), 55-67.

Kihara, J. (2005). Challenges facing university education. Nairobi: Nation Media Group.

Lion, R. W., \& Start, G. (2010). A Glance at institutional support for faculty teaching in an online learning environment. EDUCAUSE Quarterly, 33(3), 23-39.

Lu, H. P., Liu, S. H., \& Liao, H. L. (2005). Factors influencing the adoption of e-learning websites: An empirical study. Issues in Information System, 6(1), 190-196.

Luan, W. S., Aziz, A., Yunus, M. S. A., Sidek, Z., Bakar, K. A., Meseran, H., \& Atan, H. (2005). Gender differences in ICT competencies among academicians at Universiti Putra Malaysia. Online Journal of Instructional Technology, 2(3), 62-69.

MENON Network. (2007). E-learning for innovation (HELIOS Annual Report, Helsinki).

Mercado, C. A. (2008). Readiness assessment tool for an e-learning environment implementation. Proceedings from the 5th International Conference on e-learning for Knowledge-Based Society, December 11-12, Bangkok, Thailand.

Mugenda, O. M., \& Mugenda, A. G. (1999). Research methods: Quantitative and qualitative approaches. Nairobi: Acts Press.

Nachmias, C. F., \& Nachmias, D. (1996). Research methods in the social sciences (5th ed.). London: Arnold.

Naidu, S. (2006). E-learning: A guidebook of principles, procedures and practices. New Delhi: Commonwealth Educational Media Center for Asia.

Neil, T. (2004). Guiding principles for staff and student support. Distance Education, 13(1), 55-70.

Ngai, E. W., Poon, J. K., \& Chan, Y. H. (2007). Empirical examination of the use of WebCT using TAM. Computers \& Education, 48(2), 250-267.

Oblinger, D., \& Oblinger, J. (2005). Educating the net generation. Retrieved from http://www.educause.edu/eductingthenetgen

Omwenga, E. (2004). A model for introducing and implementing e-learning for delivery of educational content within the african context. African Journal of Sciences and Technology, 5(1), 35-48.

Pelgrum, W. J. (2001). Obstacles to the integration of ICT in education: Results from a worldwide educational assessment. 
Computers and Education, 37(1), 163-178.

Roberts, N., Hutchinson, W., \& Little, G. (2003). Barriers to using technology for teaching and learning in Dutch universities. Educase Quarterly, 25(2), 22-28.

Romiszowski, A. (2004). Factors leading to success or failure of an educational technology innovation. Educational Technology, 44(1), 5-27.

Rosenberg, M. J. (2001). E-learning: Strategies for building online learning in the digital age. New York: McGraw-Hill.

Saekow, A., \& Samson, D. (2011). E-learning readiness of Thailand's universities comparing to the USA's cases. International Journal of e-Education, e-Business, e-Management and e-Learning, 1(2), 554-567.

Schifter, C. C. (2000). Faculty motivators and inhibitors for participation in distance education. Educational Technology, 40(2), 43-46.

Selim, H. (2007). An empirical investigation of student acceptance of e-learning. Computers and Education, 40(1), 343-360.

Tavangarian, D., Leypold, M., Nölting, K., \& Röser, M. (2004). Is e-learning the solution for individual learning? Journal of eLearning, 1(1), 1-15.

Thurab-Nkhosi, D., Lee, M., \& Gachago, D. (2005). Preparing academic staff for e-learning at the University of Botswana. Retrieved from http://www.innovateonline.info/index.php?view=article\&id=43

Trombley, K. B., \& Lee, D. (2002). Web-based learning in corporations: Who is using it and why, who is not and why not? Journal of Educational Media, 27(3), 137-146.

US Department of Education. (2000). National center for education statistics. Teachers' tools for the 21 st century: A report on teachers' use of technology. Washington DC: NECS.

Van Braak, G. (2004). Academic staff development in online learning and teaching: Developing online pedagogies. Gold Coast: AusWeb05.

Venkatesh, V., \& Morris, M. G. (2000). Gender, social influence and their role in technology acceptance behaviour among academic staff in public universities, India. Management Information Systems Quarterly, 24(1), 115-139.

Volery, T. (2000). Critical success factors in online education. The International Journal of Educational Management, 23(2), 321-334.

Wuensch, K. L. (2006). Logistic regression with SPSS. Retrieved from http://core.ecu.edu/psyc/wuenschk/spss/logistic.sav

Ya'acob, A. (2005). Implementation of the Malaysian smart school: An investigation of teaching-learning practices and teacher-student preparedness. Internet Journal of e-Language Learning and Teaching, 2(2), 16-25. 